\title{
Uso de mantas geotêxteis na revegetação de um fragmento de mata de galeria no Jardim Botânico de Brasília - DF: sobrevivência e desenvolvimento de mudas
}

\author{
Use of geotextile collars in the revegetation of a fragment of gallery forest in the \\ Brasília Botanical Garden, Brazil: seedlings survival and development
}

\author{
Camila Graziela Artioli' ${ }^{I}$ Rodrigo Studart Corrêa ${ }^{\text {II }}$
}

\begin{abstract}
Resumo
Atividades antrópicas têm causado danos ao Cerrado, segundo maior bioma do Brasil. Entre as formações vegetais mais ameaçadas do bioma Cerrado, destaca-se a Mata de Galeria. Programas de recuperação tentam restaurar essa fitofisionomia, mas ervas invasoras dificultam o estabelecimento e o desenvolvimento de espécies nativas lenhosas. Nesse cenário, cerca de 2 ha da Mata de Galeria do Córrego Cabeça de Veado, na área do Jardim Botânico de Brasília, fora desmatada para a prática de agricultura de subsistência e, posteriormente, a área foi dominada por Melinis minutiflora Beauv. (capim-gordura). Algumas tentativas de restauração do local falharam devido à competição dessa erva com as mudas arbóreas plantadas. Dessa forma, este trabalho visou avaliar o efeito do uso de mantas geotêxteis na sobrevivência e desenvolvimento de mudas de espécies arbóreas plantadas em um trecho de Mata de Galeria infestado por capim-gordura. Na área de estudo foram plantadas mudas arbóreas de trinta espécies nativas do Cerrado. Metade das mudas recebeu manta geotêxtil e a outra metade das mudas não recebeu essa proteção. Quatro levantamentos foram efetuados, quando se mediram a sobrevivência, a altura e o diâmetro das mudas. Os resultados indicaram que as mantas geotêxteis aumentaram em $19,6 \%$ a sobrevivência de plantas e que sete das trinta espécies apresentaram maior incremento alométrico com o uso de mantas geotêxteis. Duas espécies se desenvolveram mais sem a presença de mantas geotêxteis e o incremento de metade das espécies não foi significativamente afetado pelo uso desse protetor.
\end{abstract}

Palavras-chave: Manta geotêxtil; Mata de galeria; Melinis minutiflora; Restauração ecológica

\begin{abstract}
Human activities have caused damage to Cerrado, the second largest Brazilian biome. Among the most threatened Cerrado phyto-physiognomies stand out gallery forests. Many projects have aimed at gallery forest restoration, but herb invasion hinders the establishment and development of Cerrado woody species.In this scenario, 2 ha of gallery forest along Cabeça de Veado stream within the Brasília Botanical Garden were cleared for subsistence agriculture and the area was subsequently dominated by Melinis minutiflora Beauv. (molasses grass). Some attempts at site restoration have failed due to competition between M. minutiflora and planted tree seedlings. Thus, this study aimed to evaluate the effect of using geotextile collars made of natural fibers on survival and development of Cerrado tree seedlings introduced in the area dominated by molasses grass. Seedlings of third native tree species were planted in holes chemically fertilized, and half of seedlings received geotextile collars while the other half did not for experimental control purpose. Four surveys were carried out, when survival, seedling height and diameter were measured. Results indicate that the geotextile collars increased seedlings survival in $19.6 \%$ and seven out third species achieved greater al-lometric increment from the use of geotextile collars. Increments of two species were higher in the absence of collars and the increment of half of species was not significantly affect by the geotextile protection.
\end{abstract}

Keywords: Geotextile collar; Gallery forest; Melinis minutiflora; Ecological restoration

Engenheira Florestal, MSc., Quadra 12, Conjunto B, Casa 51, CEP 73010-122, Sobradinho, Brasília (DF), Brasil. ca_graziela@homail.com (ORCID: 0000-0003-1268-4078)

II Engenheiro Agrônomo, PhD., Professor do Programa de Pós-Graduação em Ciências Ambientais, Universidade de Brasília, Caixa Postal 04.401, CEP 70842-970, Brasília (DF), Brasil. rscorrea@unb.br (ORCID: 0000-0002-9422-2629) 


\section{Introdução}

O Cerrado é o segundo maior bioma do Brasil e possui onze fitofisionomias (RIBEIRO; WALTER, 1998), que abrigam mais de doze mil espécies de plantas vasculares (MENDONÇA, 2008), sendo 44\% delas endêmicas (KLINK; MACHADO, 2005). Machado et al. (2004) calcularam que até 2002 o Cerrado já havia perdido aproximadamente $55 \%$ de sua cobertura vegetal nativa. Alto grau de endemismo, alta diversidade de espécies, vasta e rápida destruição incluíram o Cerrado brasileiro entre os 34 hotspots mundiais de conservação da biodiversidade (INTERNATIONAL UNION FOR CONSERVATION OF NATURE, 2010). Dentre as onze fitofisionomias existentes no bioma Cerrado, as Matas de Galeria estão entre as mais ameaçadas.

Programas de restauração tentam mitigar os impactos causados pelas atividades antrópicas e aumentar a capacidade de suporte de ambientes degradados (CORRÊA et al., 2015). Porém, clareiras abertas em Matas de Galerias facilitam a colonização de espécies exóticas invasoras em detrimento das espécies nativas do local. Espécies invasoras da família Poaceae e espécies do gênero Pteridium (samambaias) figuram entre as que mais frequentemente dificultam o estabelecimento de mudas de espécies arbóreas em projetos de restauração de Matas de Galeria no Distrito Federal (FELFILI et al., 2001). Martins et al. (2007) encontraram 28 espécies exóticas da família Poaceae colonizando projeto de restauração de fragmento de Cerrado no Distrito Federal. Entre elas, os autores destacaram a espécie Melinis minutiflora Beauv. (capim-gordura), conhecida por sua agressividade, resistência e resiliência. Queima controlada e outros manejos não foram capazes de controlar o capim-gordura em projetos de recuperação de área degradada (MARTINS et al., 2004).

Nesse sentido, o uso de barreiras físicas tem se mostrado promissor para o controle de ervas invasoras em plantios de árvores. Mantas geotêxteis são amplamente utilizadas na Europa e em projetos de geotécnica e revegetação de áreas mineradas no Brasil (ROCHA, 2006). Todavia, o uso de mantas geotêxteis em projetos de revegetação de Matas de Galeria no Distrito Federal não foi testado, e esse protetor pode ser uma alternativa viável para o controle de espécies invasoras em projetos de restauração dessa fitofisionomia (POLSTER, 2002; HOLANDA; ROCHA; OLIVEIRA, 2008). Dessa forma, este trabalho visa avaliar o efeito do uso de mantas geotêxteis na sobrevivência e desenvolvimento de mudas de espécies arbóreas plantadas em um trecho de Mata de Galeria, em área dominada por capim-gordura (Melinis minutiflora Beauv.).

\section{Material e métodos}

\section{Área de estudo}

O trabalho foi desenvolvido em uma área de dois hectares (2 ha) na Mata de Galeria do Córrego Cabeça de Veado, localizada na Estação Ecológica do Jardim Botânico de Brasília JBB, Distrito Federal. A Estação Ecológica do JBB ocupa uma área de 4.429,63 ha (DISTRITO FEDERAL, 1996) e faz parte da Área de Proteção Ambiental (APA) Gama-Cabeça de Veado. A área de estudo apresentava-se sobre Organossolo (EMBRAPA, 2014) e se associava às coordenadas $15^{\circ} 52^{\prime} 57.05^{\prime}$ Sul e $47^{\circ} 50^{\prime} 28.50^{\prime}$ ' Oeste (Datum WGS 84). De acordo com a classificação de Köppen, o clima predominante do local é o Tropical de Savana $(\mathrm{Aw})$, tendo verão úmido e inverno seco. A precipitação média anual varia de $1.200 \mathrm{~mm}$ a $1.700 \mathrm{~mm}$, e o período chuvoso começa em outubro e termina em abril, representando $84 \%$ da precipitação total anual.

Antes da criação da Estação Ecológica do Jardim Botânico de Brasília, há aproximadamente vinte anos, a área de estudo fora desmatada para dar lugar a uma chácara de subsistência. Atualmente, há na área uma clareira, cuja cobertura vegetal é dominada por Melinis minutiflora (capim-gordura). Exemplares de embaúba (Cecropia sp), remanescentes de plantios anteriores, formam um esparso estrato arbóreo no local. 


\section{Revegetação da área}

Para instalação do experimento, o capim-gordura, que se eleva a 1,5 m da superfície do solo, foi aparado com roçadeiras costais com fios de nylon. Covas de $80 \mathrm{~cm}$ de profundidade e 30 $\mathrm{cm}$ de diâmetro foram abertas com trado mecânico no espaçamento de 1,5 $\mathrm{m} \mathrm{x} \mathrm{3,0} \mathrm{m.} \mathrm{Cada} \mathrm{cova}$ recebeu 200 g de NPK 4-14-8 e 100 g de calcário.

Em fevereiro de 2009, foram plantadas 1.373 mudas distribuídas em trinta espécies selecionadas em um arranjo com $52 \%$ de espécies pioneiras, $41 \%$ de espécies secundárias e $7 \%$ de espécies climácicas (Tabela 1). Imediatamente após o plantio, metade das mudas recebeu um colar de manta geotêxtil, que cobria $1 \mathrm{~m}^{2}$ de área no entorno de cada planta, e metade das mudas permaneceu sem essa proteção.

\section{Tabela 1 - Espécies utilizadas no projeto de restauração na Mata de Galeria do Córrego Cabeça de Veado, na Estação Ecológica do Jardim Botânico de Brasília - DF.}

Table 1 - Species used in the restoration project of the Gallery Forest along Cabeça de Veado stream within the Ecological Station of the Brasília Botanical Garden, Brazil.

\begin{tabular}{|c|c|c|c|c|}
\hline Família & Nome Científico & Nome comum & $\begin{array}{c}\text { Grupo } \\
\text { Ecológico } \\
\end{array}$ & Fitofisionomia \\
\hline \multirow{2}{*}{ Anacardiaceae } & $\begin{array}{c}\text { Astronium } \\
\text { fraxinifolium Schott }\end{array}$ & Gonçaleiro & $\mathrm{P}$ & Mata de Galeria \\
\hline & $\begin{array}{c}\text { Myracrodruon } \\
\text { urundeuva Allemão }\end{array}$ & Aroeira & $S$ & Cerradão \\
\hline Arecaceae & $\begin{array}{c}\text { Oenocarpus bacana } \\
\text { Mart } \\
\end{array}$ & Bacaba & - & Várzea \\
\hline \multirow{4}{*}{ Bignoniaceae } & $\begin{array}{l}\text { Jacaranda brasiliana } \\
\text { (Lam.) Pers. }\end{array}$ & Caroba & $\mathrm{P}$ & $\begin{array}{c}\text { Mata de Galeria } \\
\text { Cerradão }\end{array}$ \\
\hline & $\begin{array}{l}\text { Tabebuia impetiginosa } \\
\text { (Mart. Ex DC) Standl. }\end{array}$ & Ipê-roxo & $S$ & Mata Ciliar \\
\hline & $\begin{array}{l}\text { Tabebuia roseo-alba } \\
\text { (Ridley) Sandwith }\end{array}$ & Ipê-branco & $S$ & Mata de Galeria \\
\hline & $\begin{array}{c}\text { Tabebuia serratifolia } \\
\text { (Vahl) Nicholson }\end{array}$ & Ipê-amarelo & $\mathrm{C}$ & Mata de Galeria \\
\hline \multirow{2}{*}{ Bombacaceae } & $\begin{array}{c}\text { Ceiba speciosa (A. St.- } \\
\text { Hil.) Ravenna }\end{array}$ & Barriguda & $\mathrm{P}$ & $\begin{array}{l}\text { Mata Ciliar } \\
\text { Várzea }\end{array}$ \\
\hline & $\begin{array}{c}\text { Chorisia speciosa St. } \\
\text { Hil. }\end{array}$ & Paineira & $\mathrm{P}$ & Mata Ciliar \\
\hline Boraginaceae & $\begin{array}{c}\text { Cordia trichotoma } \\
\text { (Vell.) Arrab. Ex } \\
\text { Stend. }\end{array}$ & Louro-preto & $S$ & $\begin{array}{c}\text { Mata de Galeria } \\
\text { Cerradão }\end{array}$ \\
\hline Clusiaceae & $\begin{array}{c}\text { Calophyllum } \\
\text { brasiliense Camb. }\end{array}$ & Landim & $S$ & Mata de Galeria \\
\hline Combretaceae & $\begin{array}{l}\text { Terminalia argentea } \\
\text { Mart. \& Zucc. }\end{array}$ & Capitão-do-mato & $\mathrm{P}$ & $\begin{array}{c}\text { Mata de Galeria } \\
\text { Cerradão }\end{array}$ \\
\hline
\end{tabular}

Continua... 
Tabela 1 - Conclusão...

Table 1 - Conclusion...

\begin{tabular}{|c|c|c|c|c|}
\hline Família & Nome Científico & Nome comum & $\begin{array}{l}\text { Grupo } \\
\text { Ecológico }\end{array}$ & Fitofisionomia \\
\hline Euphorbiaceae & $\begin{array}{c}\text { Mabea fistulifera } \\
\text { Mart. }\end{array}$ & Mamoninha & $\mathrm{P}$ & Cerrado \\
\hline \multirow{10}{*}{ Fabaceae } & $\begin{array}{c}\text { Acacia farnesiana (L.) } \\
\text { Willd. }\end{array}$ & Esponjinha & $P$ & $\begin{array}{c}\text { Cerrado } \\
\text { Mata Semidecídua }\end{array}$ \\
\hline & $\begin{array}{c}\text { Copaifera langsdorffii } \\
\text { Desf. }\end{array}$ & Copaíba & $S$ & $\begin{array}{l}\text { Mata de Galeria } \\
\text { Cerradão }\end{array}$ \\
\hline & $\begin{array}{c}\text { Enterolobium } \\
\text { contortisiliquum (Vell.) } \\
\text { Morong. }\end{array}$ & Tamboril & $S$ & Cerradão \\
\hline & Hymenaea courbaril L. & Jatobá-da-mata & S & $\begin{array}{c}\text { Cerradão } \\
\text { Mata de Galeria }\end{array}$ \\
\hline & $\begin{array}{c}\text { Inga cylindrica (Vell.) } \\
\text { Mart. }\end{array}$ & Ingá & $\mathrm{P}$ & Mata Ciliar \\
\hline & Inga edulis Mart. & Ingá & $\mathrm{P}$ & Mata de Galeria \\
\hline & $\begin{array}{l}\text { Inga laurina (Sw.) } \\
\text { Willd. }\end{array}$ & Ingá & $\mathrm{P}$ & $\begin{array}{l}\text { Mata Ciliar } \\
\text { Várzea }\end{array}$ \\
\hline & $\begin{array}{l}\text { Ormosia stipularis } \\
\text { Ducke }\end{array}$ & Tento & $\mathrm{P}$ & Mata de Galeria \\
\hline & $\begin{array}{l}\text { Piptadenia rigida } \\
\text { Benth. }\end{array}$ & Angico-vermelho & $\mathrm{P}$ & Mata Latifoliada \\
\hline & $\begin{array}{c}\text { Plathymenia reticulada } \\
\text { Benth. }\end{array}$ & Vinhático-cascudo & $S$ & Cerrado \\
\hline Melastomataceae & Tibouchina SP & Quaresmeira & $\mathrm{P}$ & Mata de Galeria \\
\hline Meliaceae & Cedrela fissilis Vell. & Cedro-rosa & S & Mata Ciliar \\
\hline Polygonaceae & $\begin{array}{c}\text { Triplaris brasiliana } R . \\
\text { H. Schomb. }\end{array}$ & Pau-de-formiga & $S$ & Mata ciliar \\
\hline Rubiaceae & Genipa americana $L$. & Jenipapo & C & $\begin{array}{c}\text { Mata de Galeria } \\
\text { Cerradão }\end{array}$ \\
\hline \multirow{2}{*}{ Sapindaceae } & $\begin{array}{c}\text { Dilodendron } \\
\text { bipinnatum Radlk. }\end{array}$ & Maria-pobre & $\mathrm{P}$ & Mata seca \\
\hline & $\begin{array}{c}\text { Magonia pubescens A. } \\
\text { St. Hil. }\end{array}$ & Tingui & $S$ & Cerrado \\
\hline Sterculiaceae & $\begin{array}{l}\text { Guazuma ulmifolia } \\
\text { Lam. }\end{array}$ & Mutamba & $\mathrm{P}$ & Cerrado \\
\hline
\end{tabular}

Em que: $\mathrm{P}$ = pioneira; $\mathrm{S}$ = secundária; C = clímax. Fonte: Fonseca et al. (2001); Lorenzi (2002a; 2002b); Mendonça (2008); Silva Júnior e Pereira (2009). 
Análise do solo

Amostras compostas por dez subamostras de solo foram coletadas das covas que receberam adubação e manta geotêxtil (tratamento), das covas que receberam adubação, mas não receberam manta geotêxtil (controle), e em área que não recebeu adubação. As amostras foram deixadas secar à sombra, peneiradas $(2 \mathrm{~mm})$ e levadas ao laboratório para análise de atributos químicos.

Carbono orgânico foi determinado pelo método da combustão úmida (Walkley-Black) e posterior titulação com uma solução $0,05 \mathrm{M}$ de sulfato ferroso amoniacal. Os resultados de carbono orgânico foram multiplicados por 1,724 para se estimar a concentração de matéria orgânica. $\mathrm{O}$ pH foi medido com potenciômetro em uma solução 1:2,5 de solo-água. Fósforo disponível (P-disponível), potássio trocável (K-trocável) e zinco $\left(\mathrm{Zn}^{+2}\right)$ foram extraídos com solução Mehlich I $\left(0,025 \mathrm{~N} \mathrm{H}_{2} \mathrm{SO}_{4}+0,05 \mathrm{~N} \mathrm{HCl}\right)$. As concentrações de P-disponível foram determinadas em fotocolorímetro a $660 \mathrm{~nm}$ e as concentrações de K-trocável e $\mathrm{Zn}^{+2}$, em espectrofotômetro de absorção atômica com chama. Alumínio $\left(\mathrm{Al}^{+3}\right)$, cálcio $\left(\mathrm{Ca}^{+2}\right)$ e magnésio $\left(\mathrm{Mg}^{+2}\right)$ foram extraídos com uma solução de $\mathrm{KCl} 1 \mathrm{~N}$. A concentração de $\mathrm{Al}^{+3}$ foi determinada por titulação com $\mathrm{NaOH}(0,01 \mathrm{~N})$ e as concentrações de $\mathrm{Ca}^{+2}$ e $\mathrm{Mg}^{+2}$ foram obtidas em espectrofotômetro de absorção atômica com chama. Acidez potencial $\left(\mathrm{H}^{+}+\mathrm{Al}^{+3}\right)$ foi determinada por meio de uma solução tamponada de acetado de cálcio $0,5 \mathrm{M}$ e posterior titulação com NaOH 0,05 M.

A partir dos resultados obtidos, foram calculadas a capacidade de troca catiônica (CTC a pH 7), a soma de bases (S) e a porcentagem de saturação por bases (V\%), conforme Embrapa (1997). Os resultados foram submetidos à Análise de Variância e teste de Tukey (P $<0,05)$.

\section{Coleta dos dados}

Para avaliar a influência das mantas geotêxteis sobre a sobrevivência e o desenvolvimento das espécies selecionadas, foram realizados quatro levantamentos em 27 meses. O primeiro levantamento foi realizado em abril de 2009 , o segundo em outubro de 2009, o terceiro levantamento em julho de 2010 e o quarto levantamento, em julho de 2011. Em cada levantamento contou-se o número de plantas sobreviventes, mediu-se o diâmetro a $5 \mathrm{~cm}$ do solo $\left(D_{5}\right)$ e a altura do coleto da planta até última folha apical $(\mathrm{H})$. O diâmetro foi medido com paquímetro analógico, dotado de escala de Vernier e com precisão de $0,1 \mathrm{~mm}$. A altura, com régua graduada em centímetros.

Análise de dados

Os dados de altura $(\mathrm{H})$ e diâmetro $\left(\mathrm{D}_{5}\right)$ foram combinados em um modelo alométrico baseado no volume das plantas:

$$
\mathrm{V}=\mathrm{H} \pi\left(\frac{D_{5}}{2}\right)^{2}
$$

Em que: $\mathrm{V}=$ volume $\left(\mathrm{cm}^{3}\right)$;

$\mathrm{H}=$ altura das plantas $(\mathrm{cm})$

$\pi=3,1416 ; \mathrm{D}_{5}=$ diâmetro a $5 \mathrm{~cm}$ da superfície do solo. 
Os valores médios do volume de cada espécie em cada levantamento foram utilizados para representar o incremento das plantas $(\hat{Y})$ durante os meses avaliados $(\mathrm{X})$ por meio de equações lineares $(\hat{Y}=a+b X)$ para cada espécie, com e sem manta geotêxtil. A comparação entre o incremento volumétrico das mudas com manta geotêxtil (tratamento) e sem mantas geotêxteis (controle) baseou-se na comparação dos coeficientes angulares (b) das equações descritas pelas retas, conforme Barbarick e Ippolito (2000) e Corrêa et al. (2008). Quanto maior o incremento da planta, mais inclinada é a reta que representa esse incremento. Os coeficientes angulares que descreveram o incremento volumétrico de cada espécie, com e sem manta geotêxtil, foram comparados por meio do Teste F (SNEDECOR; COCHRAN, 1989). Desse modo, o quociente das variâncias retrata o efeito do uso da manta geotêxtil sobre o desenvolvimento da espécie em questão.

\section{Resultados e discussão}

\section{Solo}

Os teores de matéria orgânica e de nutrientes no Organossolo da área de estudo que não recebeu adubação encontram-se de acordo com os valores esperados em solos dessa ordem (EMBRAPA, 2014), apesar do desmatamento e da prática da agricultura no local. A adição de fertilizantes antes do plantio das mudas arbóreas elevou significativamente os teores de P-disponível, cálcio, magnésio, cobre, ferro, soma de bases (S) e capacidade de troca catiônica (CTC) dos substratos das covas em relação ao solo original (Tabela 2). Não houve diferença significativa entre os valores dos atributos químicos analisados nos substratos das covas que receberam manta geotêxtil e daquelas que não receberam esse protetor (Tabela 2). Dessa forma, as mudas protegidas por mantas geotêxteis e as mudas sem esse protetor se desenvolveram sob condições edáficas similares, mas superiores àquelas apresentadas pelo solo nativo.

A fertilização deve ser entendida como um mecanis mo de aceleração do crescimento dos vegetais (GONÇALVES et al., 2004), para lhes fornecer vantagens competitivas em ambientes em recuperação. Plantas em bom estado nutricional apresentam maior resistência a períodos de estiagem e ao ataque de pragas e patógenos (CORREA A, 2009). A maioria das espécies nativas do Cerrado é adaptada à baixa fertilidade química dos solos, mas essas espécies respondem bem à calagem e à adubação (HARIDASAN, 2000).

A eficiência no uso de nutrientes dos solos é frequentemente mais importante do que competição por luz para a sobrevivência e estabelecimento de plantas nos estágios iniciais de desenvolvimento (VAZ; GONÇALVES, 2002). Grande parte dos nutrientes que sustentam comunidades vegetais vem da serrapilheira e da translocação interna de nutrientes nas plantas. Portanto, plantas bem nutridas nos estágios iniciais de desenvolvimento possuirão maiores quantidades de nutrientes na biomassa e, consequentemente, haverá uma maior quantidade de nutrientes nas diversas fases dos ciclos biogeoquímicos para sustentação da comunidade vegetal na área recuperada (GONÇALVES et al., 2004). 


\section{Tabela 2 - Atributos analisados nas amostras de solo coletadas na área de estudo.}

Table 2 - Analyzed attributes in soil samples collected from the study area.

\begin{tabular}{lccc}
\hline \multicolumn{1}{c}{ Atributo } & Solo da área & $\begin{array}{c}\text { Solo de covas sem } \\
\text { manta geotêxtil }\end{array}$ & $\begin{array}{c}\text { Solo de covas com manta } \\
\text { geotêxtil }\end{array}$ \\
\hline Matéria orgânica $\left(\mathrm{g} \mathrm{kg}^{-1}\right)$ & $70,0 \mathrm{a}$ & $70,5 \mathrm{a}$ & $69,9 \mathrm{a}$ \\
$\mathrm{pH}($ água $)$ & $5,4 \mathrm{a}$ & $5,3 \mathrm{a}$ & $5,3 \mathrm{a}$ \\
$\mathrm{P}$-disponível $\left(\mathrm{mg} \mathrm{kg}^{-1}\right)$ & $9,1 \mathrm{a}$ & $106,5 \mathrm{~b}$ & $104,6 \mathrm{~b}$ \\
$\mathrm{~K}\left(\mathrm{mmol}_{\mathrm{c}} \mathrm{kg}^{-1}\right)$ & $1,3 \mathrm{a}$ & $1,7 \mathrm{~b}$ & $1,5 \mathrm{ab}$ \\
$\mathrm{Ca}\left(\mathrm{mmol}_{\mathrm{c}} \mathrm{kg}^{-1}\right)$ & $73,2 \mathrm{a}$ & $93,1 \mathrm{~b}$ & $96,2 \mathrm{~b}$ \\
$\mathrm{Mg}\left(\mathrm{mmol}_{\mathrm{c}} \mathrm{kg}^{-1}\right)$ & $13,3 \mathrm{a}$ & $16,2 \mathrm{~b}$ & $14,7 \mathrm{ab}$ \\
$\mathrm{Soma} \mathrm{de} \mathrm{bases}\left(\mathrm{mmol}_{\mathrm{c}} \mathrm{kg}^{-1}\right)$ & $86,7 \mathrm{a}$ & $111,0 \mathrm{~b}$ & $112,4 \mathrm{~b}$ \\
$\mathrm{CTC}\left(\mathrm{mmol}_{\mathrm{c}} \mathrm{kg}^{-1}\right)$ & $133,7 \mathrm{a}$ & $160,8 \mathrm{~b}$ & $158,7 \mathrm{~b}$ \\
$\mathrm{~V}(\%)$ & $64,8 \mathrm{a}$ & $69,0 \mathrm{a}$ & $69,2 \mathrm{a}$ \\
$\mathrm{B}\left(\mathrm{mg} \mathrm{kg}^{-1}\right)$ & $0,17 \mathrm{a}$ & $0,17 \mathrm{a}$ & $0,19 \mathrm{a}$ \\
$\mathrm{Cu}\left(\mathrm{mg} \mathrm{kg}^{-1}\right)$ & $0,7 \mathrm{a}$ & $1,8 \mathrm{~b}$ & $1,6 \mathrm{~b}$ \\
$\mathrm{Fe}\left(\mathrm{mg} \mathrm{kg}^{-1}\right)$ & $34,1 \mathrm{a}$ & $41,0 \mathrm{~b}$ & $39,9 \mathrm{~b}$ \\
$\mathrm{Mn}\left(\mathrm{mg} \mathrm{kg}^{-1}\right)$ & $13,9 \mathrm{a}$ & $8,2 \mathrm{~b}$ & $7,8 \mathrm{~b}$ \\
$\mathrm{Zn}\left(\mathrm{mg} \mathrm{kg}^{-1}\right)$ & $1,2 \mathrm{a}$ & $1,8 \mathrm{a}$ & $2,1 \mathrm{a}$ \\
\hline
\end{tabular}

Médias de mesma letra em cada linha não diferem pelo teste de Tukey $(\mathrm{P}<0,05)$.

\section{Desenvolvimento das mudas}

As 1.373 mudas plantadas na área de estudo encontravam-se distribuídas em trinta espécies de quinze famílias (Tabela 3). As famílias com maior número de espécies foram Fabaceae (10) e Bignoniaceae (4), muito utilizadas em programas de recuperação de áreas degradadas (CORREAA, 2009). Várias espécies nativas do Cerrado que pertencem a essas famílias são rústicas, desenvolvem-se bem sob condições de plena luz, em várias condições de fertilidade e tipos de solo, e muitas espécies da família Fabaceae incorporam nitrogênio ao solo por meio de bactérias do gênero Rhizobium (CORRÊA, 2009). Sob condições naturais, Ribeiro e Walter (1998) relatam o significativo número de espécies que representam a família Fabaceae nas Matas de Galeria do bioma Cerrado. Em levantamentos florísticos realizados por Silva Júnior et al. $(1998 ; 2001)$ em Matas de Galeria do Distrito Federal, a família Fabaceae estava representada por 26 gêneros e 46 espécies amostradas. Essa família predomina nessa fitofisionomia no Centro Oeste brasileiro, com áreas basais expressivas. Espécies arbóreas da família Fabaceae podem funcionar como facilitadoras da sucessão em áreas degradadas, pela capacidade de melhorarem as condições dos sítios em processo de recuperação (MOCHIUTTI et al., 2008).

No primeiro levantamento deste trabalho foram detectadas 1.213 mudas vivas, sendo 724 protegidas por mantas geotêxteis e 489 sem mantas geotêxteis. Dois meses e meio após o plantio, ainda na estação chuvosa, $12 \%$ das plantas não haviam sobrevivido. No segundo levantamento, ao final do período seco, a mortalidade de mudas atingiu $30 \%$ em relação ao número inicial. Dessa forma, ao final do primeiro período de estiagem, foram medidas 972 mudas, das quais 639 estavam protegidas com mantas geotêxteis e 333 sem manta geotêxtil. Portanto, após os seis primeiros meses de desenvolvimento no campo, a percentagem de sobrevivência das mudas com 
manta geotêxtil foi de $88,3 \%$ e das mudas sem manta geotêxtil foi de $68,1 \%$ (Tabela 3).

Aos dezoito meses após o plantio, o capim-gordura (Melinis minutiflora Beauv) havia reinfestado a área de estudo, quando apenas 256 mudas puderam ser encontradas e medidas. Dessa forma, houve a necessidade de capina da área e aos 27 meses após o plantio foram medidas 700 mudas, sendo 475 protegidas com manta geotêxtil e 225 sem manta geotêxtil. Nesse levantamento, a sobrevivência das mudas que receberam manta geotêxtil foi de $65,6 \%$ e das que não receberam esse protetor foi de $46,0 \%$. Na avaliação aos 27 meses, as mantas geotêxteis ainda se faziam presentes nas superfícies das covas em que foram aplicadas (Tabela 4).

A percentagem de sobrevivência geral, após 27 meses no campo, foi de 57,7\% (Tabela 4). No estudo de Moura (2008), desenvolvido na Mata de Galeria do Ribeirão do Gama, próximo à área deste trabalho, a sobrevivência aos dezesseis meses após o plantio foi de $72,7 \%$. Pinto et al. (2007), ao recuperarem uma área degradada e invadida por Brachiaria spp., consideraram satisfatória a sobrevivência de $57 \%$ das mudas plantadas.

Outros estudos sobre plantios em Matas de Galeria no Cerrado obtiveram entre 84\% e 92\% de sobrevivência das espécies Enterolobium contortisiliquum, Genipa americana e Triplaris americana (FONSECA et al., 2001). No presente estudo, a espécie Enterolobium contortisiliquum apresentou $100 \%$ de sobrevivência aos seis meses de idade, independentemente da proteção fornecida pelas mantas geotêxteis. A percentagem de sobrevivência de Genipa americana foi de $96,6 \%$ para as mudas que receberam manta geotêxtil e de $61,1 \%$ para as mudas que não receberam a manta geotêxtil. Algumas espécies, tais como Acacia farnesiana, Cedrela fissilis, Dilodendron bipinnatum e outras apresentaram maior porcentagem de sobrevivência de mudas protegidas por mantas geotêxteis. Outras, tais como Cordia trichotoma, Hymenaea courbaril, Inga laurina e Jacaranda brasiliana, sobreviveram mais sem essa proteção. Há ainda um terceiro grupo de espécies, cuja sobrevivência não foi afetada pelo tratamento (Tabelas 3 e 4).

\section{Tabela 3 - Percentual de sobrevivência das mudas plantadas na área de estudo, observado aos seis meses de desenvolvimento.}

Table 3 - Percentage survival of the seedlings planted in the study area after six months of development.

\begin{tabular}{|c|c|c|c|c|}
\hline Nome Científico & Grupo Ecológico & Fitofisionomia & $\begin{array}{c}\text { Sobrevivência } \\
\text { com manta } \\
\text { geotêxtil (\%) }\end{array}$ & $\begin{array}{c}\text { Sobrevivência } \\
\text { sem manta } \\
\text { geotêxtil (\%) }\end{array}$ \\
\hline Acacia farnesiana & $\mathrm{P}$ & Cerrado & 100,0 & 0,0 \\
\hline $\begin{array}{l}\text { Astronium } \\
\text { fraxinifolium }\end{array}$ & $\mathrm{P}$ & Mata de Galeria & 42,9 & 0,0 \\
\hline $\begin{array}{l}\text { Calophyllum } \\
\text { brasiliense }\end{array}$ & S & Mata de Galeria & 77,8 & 68,2 \\
\hline Cedrela fissilis & S & Mata Ciliar & 100,0 & 13,3 \\
\hline Ceiba speciosa & $\mathrm{P}$ & $\begin{array}{l}\text { Mata Ciliar } \\
\text { Várzea }\end{array}$ & 100,0 & 85,7 \\
\hline Chorisia speciosa & $\mathrm{P}$ & Mata Ciliar & 58,3 & 30,0 \\
\hline $\begin{array}{l}\text { Copaifera } \\
\text { langsdorffii }\end{array}$ & S & $\begin{array}{l}\text { Mata de Galeria } \\
\text { Cerradão }\end{array}$ & 90,5 & 61,5 \\
\hline Cordia trichotoma & S & $\begin{array}{l}\text { Mata de Galeria } \\
\text { Cerradão }\end{array}$ & 81,8 & 100,0 \\
\hline
\end{tabular}


Tabela 3 - Conclusão...

Table 3-Conclusion...

\begin{tabular}{|c|c|c|c|c|}
\hline Nome Científico & Grupo Ecológico & Fitofisionomia & $\begin{array}{c}\text { Sobrevivência } \\
\text { com manta } \\
\text { geotêxtil (\%) }\end{array}$ & $\begin{array}{c}\text { Sobrevivência } \\
\text { sem manta } \\
\text { geotêxtil (\%) }\end{array}$ \\
\hline $\begin{array}{l}\text { Dilodendron } \\
\text { bipinnatum }\end{array}$ & $\mathrm{P}$ & Mata seca & 100,0 & 38,5 \\
\hline $\begin{array}{l}\text { Enterolobium } \\
\text { contortisiliquum }\end{array}$ & $S$ & Cerradão & 100,0 & 100,0 \\
\hline Genipa americana & $\mathrm{C}$ & $\begin{array}{c}\text { Mata de Galeria } \\
\text { Cerradão }\end{array}$ & 96,6 & 61,1 \\
\hline $\begin{array}{l}\text { Guazuma } \\
\text { ulmifolia }\end{array}$ & $P$ & Cerrado & 83,3 & 60,0 \\
\hline $\begin{array}{l}\text { Hymenaea } \\
\text { courbaril }\end{array}$ & S & $\begin{array}{c}\text { Cerradão } \\
\text { Mata de Galeria }\end{array}$ & 62,5 & 100,0 \\
\hline Inga cylindrica & $\mathrm{P}$ & Mata Ciliar & 100,0 & 84,2 \\
\hline Inga edulis & $\mathrm{P}$ & Mata de Galeria & 73,9 & 65,0 \\
\hline Inga laurina & $\mathrm{P}$ & $\begin{array}{l}\text { Mata Ciliar } \\
\text { Várzea }\end{array}$ & 86,2 & 100,0 \\
\hline $\begin{array}{l}\text { Jacaranda } \\
\text { brasiliana }\end{array}$ & $\mathrm{P}$ & $\begin{array}{c}\text { Mata de Galeria } \\
\text { Cerradão }\end{array}$ & 80,0 & 100,0 \\
\hline Mabea fistulifera & $\mathrm{P}$ & Cerrado & 0,0 & 0,0 \\
\hline $\begin{array}{l}\text { Magonia } \\
\text { pubescens }\end{array}$ & $S$ & Cerrado & 14,3 & 0,0 \\
\hline $\begin{array}{l}\text { Myracrodruon } \\
\text { urundeuva }\end{array}$ & $S$ & Cerradão & 92,0 & 82,6 \\
\hline $\begin{array}{l}\text { Oenocarpus } \\
\text { bacana }\end{array}$ & - & Várzea & 0,0 & 66,7 \\
\hline Ormosia stipularis & $\mathrm{P}$ & Mata de Galeria & 0,0 & 0,0 \\
\hline Piptadenia rigida & $\mathrm{P}$ & Mata Latifoliada & 80,0 & 39,1 \\
\hline $\begin{array}{l}\text { Plathymenia } \\
\text { reticulada }\end{array}$ & S & Cerrado & 90,0 & 42,9 \\
\hline $\begin{array}{l}\text { Tabebuia } \\
\text { impetiginosa }\end{array}$ & $\mathrm{s}$ & Mata Ciliar & 76,5 & 36,4 \\
\hline $\begin{array}{l}\text { Tabebuia roseo- } \\
\text { alba }\end{array}$ & $S$ & Mata de Galeria & 94,1 & 78,1 \\
\hline $\begin{array}{l}\text { Tabebuia } \\
\text { serratifolia }\end{array}$ & C & Mata de Galeria & 100,0 & 65,5 \\
\hline $\begin{array}{l}\text { Terminalia } \\
\text { argentea }\end{array}$ & $\mathrm{P}$ & $\begin{array}{l}\text { Mata de Galeria } \\
\text { Cerradão }\end{array}$ & 95,7 & 73,9 \\
\hline Tibouchina sp & $\mathrm{P}$ & Mata de Galeria & 84,6 & 92,3 \\
\hline $\begin{array}{l}\text { Triplaris } \\
\text { brasiliana }\end{array}$ & S & Mata ciliar & 89,4 & 74,4 \\
\hline
\end{tabular}

Fonte: Autores (2019) 
Tabela 4 - Percentual de sobrevivência das mudas plantadas na área de estudo, observado aos 27 meses de desenvolvimento.

Table 4 - Percentage survival of the seedlings planted in the study area after 27 months of development.

\begin{tabular}{|c|c|c|c|c|}
\hline Nome Científico & $\begin{array}{l}\text { Grupo } \\
\text { Ecológico }\end{array}$ & Fitofisionomia & $\begin{array}{l}\text { Sobrevivência } \\
\text { com manta } \\
\text { geotêxtil (\%) }\end{array}$ & $\begin{array}{c}\text { Sobrevivência } \\
\text { sem manta } \\
\text { geotêxtil (\%) }\end{array}$ \\
\hline Acacia farnesiana & $\mathrm{P}$ & Cerrado & 83,3 & 0,0 \\
\hline Astronium fraxinifolium & $\mathrm{P}$ & Mata de Galeria & 28,6 & 0,0 \\
\hline Calophyllum brasiliense & S & Mata de Galeria & 66,7 & 54,5 \\
\hline Cedrela fissilis & S & Mata Ciliar & 64,7 & 13,3 \\
\hline Ceiba speciosa & $\mathrm{P}$ & $\begin{array}{l}\text { Mata Ciliar } \\
\text { Várzea }\end{array}$ & 90,2 & 57,1 \\
\hline Chorisia speciosa & $\mathrm{P}$ & Mata Ciliar & 45,8 & 30,0 \\
\hline Copaifera langsdorffii & S & $\begin{array}{l}\text { Mata de Galeria } \\
\text { Cerradão }\end{array}$ & 71,4 & 66,7 \\
\hline Cordia trichotoma & $S$ & $\begin{array}{l}\text { Mata de Galeria } \\
\text { Cerradão }\end{array}$ & 72,7 & 0,0 \\
\hline Dilodendron bipinnatum & $\mathrm{P}$ & Mata seca & 100,0 & 46,2 \\
\hline Enterolobium contortisiliquum & S & Cerradão & 77,8 & 60,0 \\
\hline Genipa americana & $\mathrm{C}$ & $\begin{array}{l}\text { Mata de Galeria } \\
\text { Cerradão }\end{array}$ & 75,9 & 58,3 \\
\hline Guazuma ulmifolia & $\mathrm{P}$ & Cerrado & 58,3 & 40,0 \\
\hline Hymenaea courbaril & S & $\begin{array}{c}\text { Cerradão } \\
\text { Mata de Galeria }\end{array}$ & 56,3 & 100,0 \\
\hline Inga cylindrica & $\mathrm{P}$ & Mata Ciliar & 65,8 & 47,4 \\
\hline Inga edulis & $\mathrm{P}$ & Mata de Galeria & 60,9 & 45,0 \\
\hline Inga laurina & $\mathrm{P}$ & $\begin{array}{l}\text { Mata Ciliar } \\
\text { Várzea }\end{array}$ & 55,2 & 68,4 \\
\hline Jacaranda brasiliana & $\mathrm{P}$ & $\begin{array}{l}\text { Mata de Galeria } \\
\text { Cerradão }\end{array}$ & 60,0 & 0,0 \\
\hline Mabea fistulifera & $\mathrm{P}$ & Cerrado & 0,0 & 0,0 \\
\hline Magonia pubescens & $\mathrm{s}$ & Cerrado & 28,6 & 0,0 \\
\hline Myracrodruon urundeuva & S & Cerradão & 72,0 & 65,2 \\
\hline Oenocarpus bacana & - & Várzea & 0,0 & 33,3 \\
\hline Ormosia stipularis & $\mathrm{P}$ & Mata de Galeria & 0,0 & 33,3 \\
\hline Piptadenia rigida & $\mathrm{P}$ & Mata Latifoliada & 66,0 & 17,4 \\
\hline Plathymenia reticulada & $S$ & Cerrado & 70,0 & 28,6 \\
\hline Tabebuia impetiginosa & S & Mata Ciliar & 45,7 & 27,3 \\
\hline Tabebuia roseo-alba & S & Mata de Galeria & 56,9 & $\begin{array}{l}31,3 \\
\text { Continu }\end{array}$ \\
\hline
\end{tabular}


Tabela 4 - Conclusão...

Table 4-Conclusion...

\begin{tabular}{lcccc}
\hline Nome Científico & $\begin{array}{c}\text { Grupo } \\
\text { Ecológico }\end{array}$ & Fitofisionomia & $\begin{array}{c}\text { Sobrevivência } \\
\text { com manta } \\
\text { geotêxtil }(\mathbf{\%})\end{array}$ & $\begin{array}{c}\text { Sobrevivência } \\
\text { sem manta } \\
\text { geotêxtil (\%) }\end{array}$ \\
\hline $\begin{array}{l}\text { Tabebuia serratifolia } \\
\text { Terminalia argentea }\end{array}$ & $\mathrm{C}$ & Mata de Galeria & 88,6 & 51,7 \\
Tibouchina sp & $\mathrm{P}$ & Mata de Galeria & 84,8 & 60,9 \\
Triplaris brasiliana & $\mathrm{P}$ & Cerradão & 53,8 & 53,8 \\
\hline
\end{tabular}

Fonte: Autores (2019)

Source: Authors (2019)

Souza (2002) indicou o uso de Tabebuia serratifolia, Enterolobium contortirsiliquum, Genipa americana, Hymenaea stilbocarpa e Myracrodruon urundeuva para plantios de recuperação de Matas de Galeria no Distrito Federal. De acordo com esse autor, essas espécies apresentam rápido crescimento e sobrevivência acima de $60 \%$ em projetos de revegetação dessa fitofisionomia. Neste estudo, essas espécies apresentaram entre 72,0 e 86,6\% de indivíduos sobreviventes com manta geotêxtil e $51,7 \%-65,2 \%$ sem o uso desse protetor (Tabela 4). Silva (2007) recomenda o uso de Genipa americana, Astronium fraxinifolium, Tabebuia roseo-alba, Myracrodruon urundeuva e Plathymenia reticulata em projetos de revegetação de áreas degradadas. Nesse mesmo estudo, o autor não recomenda o uso das espécies Ormosia stipularis e Copaifera langsdorffii, porque elas apresentaram sobrevivência abaixo de $60 \%$. No Cerrado em que Antezana (2008) desenvolveu trabalho, a espécie Genipa americana apresentou $100 \%$ de sobrevivência e a espécie Calophyllum brasiliense apresentou $100 \%$ de mortalidade em doze meses sob diferentes condições de adubação e roçagem. No estudo de Rezende et al. (2006), as espécies Enterolobium contortirsiliquum, Genipa americana e Hymenaea courbaril apresentaram crescimento reduzido, mas com sobrevivência satisfatória em condições adversas. Sobrevivência e incremento são as duas principais características utilizadas para a seleção de espécies utilizadas em projetos de revegetação de áreas degradadas (CORRÊA, 2009). Resta saber se as espécies que mais sobrevivem e que apresentam maiores incrementos são também as que mais impulsionam a sucessão em áreas em processo de restauração.

\section{Incremento das mudas}

As trinta espécies plantadas na área deste estudo apresentaram diferentes incrementos volumétricos, alguns afetados pelo uso das mantas geotêxteis (Tabela 5). As equações representativas do incremento de algumas espécies não puderam ser descritas, pela falta de pelo menos três valores das medidas efetuadas.

A análise dos coeficientes angulares das retas descritas pelo incremento das mudas (teste F) mostrou que das trinta espécies estudadas, nove apresentaram incrementos significativamente diferentes como resultado do uso da manta geotêxtil: Calophyllum brasiliense, Cordia trichotoma, Hymenaea courbaril, Inga cylindrica, Jacaranda brasiliana, Myracrodruon urundeuva, Piptadenia rigida, Tabebuia impetiginosa e Tabebuia serratifolia. As mudas de Calophyllum brasiliense que não receberam a manta geotêxtil cresceram 2,4 vezes mais do que as mudas que receberam esse protetor. As mudas de Tabebuia impetiginosa que não receberam a manta geotêxtil cresceram 1,4 vezes mais do que as mudas dessa espécie que receberam o protetor. As plantas das sete outras espécies acima listadas apresentaram incrementos de até 28 vezes superiores quando protegidas 
com manta geotêxtil do que aquelas que não receberam essa proteção. Relações e mecanismos de competição e facilitação atuam em áreas sob restauração e a facilitação, aqui representada pela barreira física imposta pelas mantas geotêxteis, geralmente resulta em maiores percentuais de plantas sobreviventes e em maior incremento de espécies vegetais. Todavia, há casos em que a competição estimula o incremento vegetal, a depender das espécies envolvidas na relação e de seus respectivos estágios de desenvolvimento (POLSTER, 2002; ANTEZANA, 2008; CORRÊA et al., 2015). Outras quinze espécies avaliadas não apresentaram incrementos significativamente afetados pelo uso da manta geotêxtil. O efeito das mantas geotêxteis não pôde ser avaliado em seis espécies, das trinta utilizadas, porque elas não foram encontradas em pelo menos três dos quatro levantamentos efetuados: Acacia farnesiana, Astronium fraxinifolium, Mabea fistulifera, Magonia pubescens, Oenocarpus bacana e Ormosia stipularis.

Não se encontrou relação de dependência entre as percentagens de sobrevivência e de incremento das espécies utilizadas (Figura 1), conforme relatado em outros trabalhos (CORREA et al., 2009). As espécies que apresentaram maiores percentuais de indivíduos sobreviventes no tratamento com manta geotêxtil são diferentes das espécies que apresentaram maiores incrementos com o uso desse protetor. O mesmo se aplica aos resultados de sobrevivência e incremento das mudas utilizadas como controle. Dessa forma, o tratamento dado às mudas com as mantas geotêxteis não reuniu nas mesmas espécies maiores incrementos e maiores percentuais de indivíduos sobreviventes.

\section{Tabela 5 - Equações lineares representativas do incremento volumétrico das mudas plantadas na área de estudo.}

Table 5 - Linear equations for volumetric increment of seedlings planted in study area.

\begin{tabular}{|c|c|c|c|c|}
\hline Nome Científico & \multicolumn{2}{|c|}{ Com manta geotêxtil } & \multicolumn{2}{|c|}{ Sem manta geotêxtil } \\
\hline Acacia farnesiana (L.) Willd.* & - & & - & \\
\hline Astronium fraxinifolium Schott ${ }^{*}$ & - & & - & \\
\hline Calophyllum brasiliense Camb. & $\hat{Y} c=72,67+0,63^{a} X$ & $\mathrm{R}^{2}=0,95$ & $\hat{Y} s=40,29+1,53^{b} X$ & $\mathrm{R}^{2}=0,81$ \\
\hline Cedrela fissilis Vell. & $\hat{Y} \mathrm{c}=22,16+0,77^{a} \mathrm{X}$ & $\mathrm{R}^{2}=0,16$ & $\hat{\mathrm{Y}} \mathrm{s}=8,80+0,40^{\underline{\mathrm{a}}} \mathrm{X}$ & $\mathrm{R}^{2}=0,16$ \\
\hline $\begin{array}{l}\text { Ceiba speciosa (A. St.-Hil.) } \\
\text { Ravenna }\end{array}$ & $\hat{Y} \mathrm{c}=312,99+16,4^{\mathrm{a}} \mathrm{X}$ & $\mathrm{R}^{2}=0,83$ & $\hat{Y} s=297,2+7,22^{\underline{a}} X$ & $\mathrm{R}^{2}=0,53$ \\
\hline Chorisia speciosa St. Hil. & $\hat{Y} \mathrm{c}=175,69+9,21^{a} X$ & $\mathrm{R}^{2}=0,18$ & $\hat{Y} s=86,42+5,92^{\underline{a}} X$ & $\mathrm{R}^{2}=0,18$ \\
\hline Copaifera langsdorffii Desf. & $\hat{Y} \mathrm{c}=3,77+0,48^{\mathrm{a}} \mathrm{X}$ & $\mathrm{R}^{2}=0,91$ & $\hat{\mathrm{Y}} \mathrm{s}=7,35+0,41^{\mathrm{a}} \mathrm{X}$ & $\mathrm{R}^{2}=0,93$ \\
\hline $\begin{array}{l}\text { Cordia trichotoma (Vell.) Arrab. Ex } \\
\text { Stend. }\end{array}$ & $\hat{\mathrm{Y}} \mathrm{c}=25,91-0,12^{\mathrm{a}} \mathrm{X}$ & $\mathrm{R}^{2}=0,62$ & $\hat{\mathrm{Y}} \mathrm{s}=23,84-1,06^{\mathrm{b}} \mathrm{X}$ & $\mathrm{R}^{2}=0,79$ \\
\hline Dilodendron bipinnatum Radlk. & $\hat{Y} \mathrm{c}=10,81+1,61^{\mathrm{a}} \mathrm{X}$ & $\mathrm{R}^{2}=0,76$ & $\hat{Y} s=9,14+0,21^{\underline{a}} X$ & $\mathrm{R}^{2}=0,07$ \\
\hline $\begin{array}{l}\text { Enterolobium contortisiliquum } \\
\text { (Vell.) }\end{array}$ & $\hat{Y} c=15,95+2,75^{a} X$ & $\mathrm{R}^{2}=0,89$ & $\hat{Y} s=1,71+1,85^{a} X$ & $\mathrm{R}^{2}=0,91$ \\
\hline Genipa americana L. & $\hat{Y} \mathrm{c}=11,83+0,81^{\mathrm{a}} \mathrm{X}$ & $\mathrm{R}^{2}=0,91$ & $\hat{Y} s=8,54+1,17^{\underline{a}} \mathrm{X}$ & $\mathrm{R}^{2}=0,86$ \\
\hline Guazuma ulmifolia Lam. & $\hat{Y} \mathrm{c}=13,49+1,03^{\underline{a}} \mathrm{X}$ & $\mathrm{R}^{2}=0,90$ & $\hat{Y} s=8,95+0,83^{\underline{a}} X$ & $\mathrm{R}^{2}=0,90$ \\
\hline Hymenaea courbaril L. & $\hat{Y} c=5,88+0,78^{a} X$ & $\mathrm{R}^{2}=0,99$ & $\hat{\mathrm{Y}} \mathrm{s}=13,72+0,22^{\mathrm{b}} \mathrm{X}$ & $\mathrm{R}^{2}=0,33$ \\
\hline Inga cylindrica (Vell.) Mart. & $\hat{\mathrm{Y}} \mathrm{c}=20,15+1,14^{\underline{a}} \mathrm{X}$ & $\mathrm{R}^{2}=0,96$ & $\hat{\mathrm{Y}} \mathrm{s}=18,30+0,58^{\mathrm{b}} \mathrm{X}$ & $\mathrm{R}^{2}=0,99$ \\
\hline Inga edulis Mart. & $\hat{Y} \mathrm{c}=20,25+2,87^{\underline{a}} \mathrm{X}$ & $\mathrm{R}^{2}=0,91$ & $\hat{Y} s=19,01-0,39^{a} \mathrm{X}$ & $\mathrm{R}^{2}=0,36$ \\
\hline
\end{tabular}


Tabela 5 - Conclusão...

Table 5 -Conclusion...

\begin{tabular}{|c|c|c|c|c|}
\hline \multirow{2}{*}{$\begin{array}{r}\text { Nome Científico } \\
\text { Inga laurina }(\mathrm{Sw} .) \text { Willd. }\end{array}$} & \multicolumn{2}{|c|}{ Com manta geotêxtil } & \multicolumn{2}{|c|}{ Sem manta geotêxtil } \\
\hline & $\hat{\mathrm{Y}} \mathrm{c}=6,36+8,18^{\mathrm{a}} \mathrm{X}$ & $R^{2}=0,89$ & $\hat{\mathrm{Y}} \mathrm{s}=-4,15+6,82^{\mathrm{a}} \mathrm{X}$ & $\mathrm{R}^{2}=0,92$ \\
\hline Jacaranda brasiliana (Lam.) Pers. & $\hat{Y} c=1,19+0,28^{a} X$ & $\mathrm{R}^{2}=0,90$ & $\hat{Y} s=3,64-0,01^{b} X$ & $\mathrm{R}^{2}=0,001$ \\
\hline Mabea fistulifera Mart.* & - & & - & \\
\hline Magonia pubescens A. St. Hil. ${ }^{*}$ & - & & - & \\
\hline Myracrodruon urundeuva Allemão & $\hat{Y} \mathrm{c}=-1,83+7,34^{\mathrm{a}} \mathrm{X}$ & $\mathrm{R}^{2}=0,92$ & $\hat{Y} s=4,49+1,14^{b} X$ & $\mathrm{R}^{2}=0,71$ \\
\hline Oenocarpus bacana Mart* & - & & - & \\
\hline Ormosia stipularis Ducke* & - & & - & \\
\hline Piptadenia rigida Benth. & $\hat{Y} c=-1,05+3,88^{a} X$ & $\mathrm{R}^{2}=0,92$ & $\hat{\mathrm{Y}} \mathrm{s}=1,38+1,02^{\mathrm{b}} \mathrm{X}$ & $\mathrm{R}^{2}=0,94$ \\
\hline Plathymenia reticulada Benth. & $\hat{Y} c=4,62+0,23^{a} X$ & $\mathrm{R}^{2}=0,16$ & $\hat{Y} s=2,70+0,15^{\underline{a}} X$ & $\mathrm{R}^{2}=0,16$ \\
\hline $\begin{array}{l}\text { Tabebuia impetiginosa (Mart. Ex } \\
\text { DC) Standl. }\end{array}$ & $\hat{Y} c=88,55+3,28^{a} X$ & $\mathrm{R}^{2}=0,90$ & $\hat{Y} s=53,30+4,56^{b} X$ & $\mathrm{R}^{2}=0,81$ \\
\hline $\begin{array}{l}\text { Tabebuia roseo-alba (Ridley) } \\
\text { Sandwith }\end{array}$ & $\hat{Y} \mathrm{c}=22,18+2,10^{\mathrm{a}} \mathrm{X}$ & $\mathrm{R}^{2}=0,93$ & $\hat{\mathrm{Y}} \mathrm{s}=17,94+0,38^{\mathrm{a}} \mathrm{X}$ & $\mathrm{R}^{2}=0,62$ \\
\hline $\begin{array}{l}\text { Tabebuia serratifolia (Vahl) } \\
\text { Nicholson }\end{array}$ & $\hat{Y} \mathrm{c}=12,26+1,40^{\mathrm{a}} \mathrm{X}$ & $\mathrm{R}^{2}=0,97$ & $\hat{\mathrm{Y}} \mathrm{s}=9,40+0,43^{\mathrm{b}} \mathrm{X}$ & $\mathrm{R}^{2}=0,15$ \\
\hline Terminalia argentea Mart. \& Zucc. & $\hat{Y} \mathrm{c}=31,61+1,59^{\mathrm{a}} \mathrm{X}$ & $\mathrm{R}^{2}=0,83$ & $\hat{Y} s=23,00+1,92^{\underline{a}} X$ & $\mathrm{R}^{2}=0,83$ \\
\hline Tibouchina sp & $\hat{Y} \mathrm{c}=23,21+4,34^{\mathrm{a}} \mathrm{X}$ & $\mathrm{R}^{2}=0,92$ & $\hat{Y} s=19,15+2,80^{\underline{a}} X$ & $\mathrm{R}^{2}=0,94$ \\
\hline Triplaris brasiliana R. H. Schomb. & $\hat{\mathrm{Y}} \mathrm{c}=39,96+1,97^{\mathrm{a}} \mathrm{X}$ & $\mathrm{R}^{2}=0,97$ & $\hat{\mathrm{Y}} \mathrm{s}=26,29+1,63^{\mathrm{a}} \mathrm{X}$ & $\mathrm{R}^{2}=0,92$ \\
\hline
\end{tabular}

${ }^{*}$ Espécies que não foram observadas em pelo menos três levantamentos, necessários para análise por equação alométrica. Coeficientes angulares das equações seguidos de mesma letra em cada linha não diferem significativamente $(\mathrm{P}<0,05)$ pelo teste $\mathrm{F}$.

Figura 1 - Relação entre sobrevivência e incremento das mudas utilizadas no experimento.

Figure 1 - Relation between survival and increment of seedlings in the experiment.

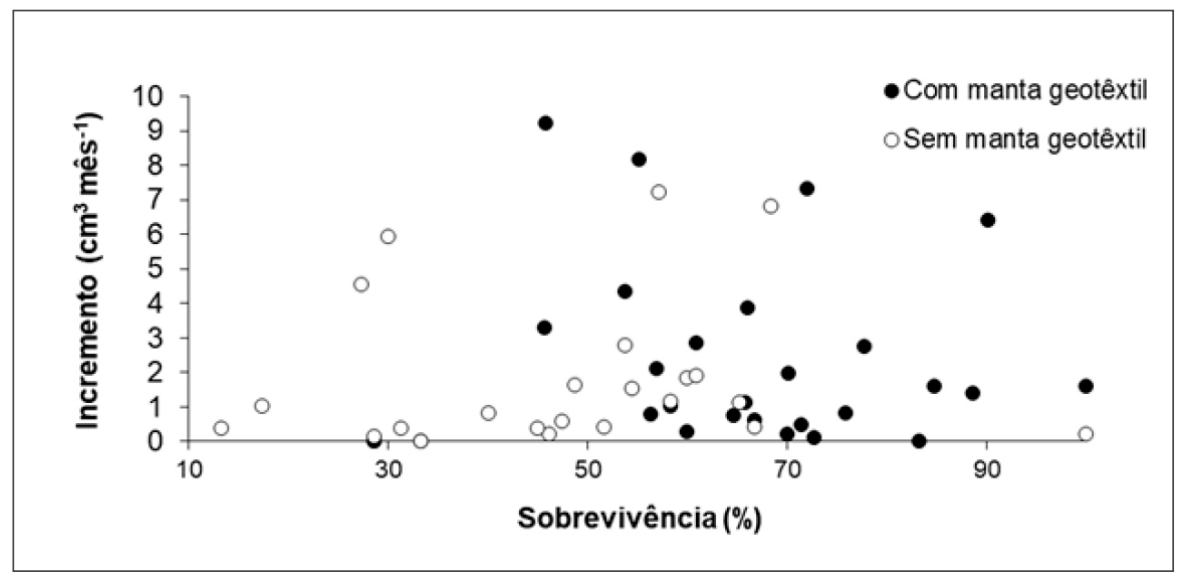

Fonte: Autores (2019)

Source: Authors (2019) 


\section{Conclusões}

Após 27 meses no campo, o percentual de indivíduos sobreviventes foi de $65,6 \%$ para as mudas que receberam manta geotêxtil e $46,0 \%$ para as mudas que não receberam esse protetor. Portanto, o uso de mantas geotêxteis como barreira física ao desenvolvimento do capim Melinis minutiflora Beauv. proporcionou uma percentagem de sobrevivência 19,6\% superior em relação às mudas que não receberam manta geotêxtil sobre a superfície de suas covas.

$\mathrm{O}$ uso de mantas geotêxteis proporcionou incrementos alométricos significativamente maiores em $23 \%$ das espécies testadas e incrementos menores em $7 \%$ das espécies. Outras quinze espécies (50\%) não apresentaram o incremento significativamente afetado pelo uso da manta geotêxtil, e $20 \%$ das espécies não apresentaram número suficiente de sobreviventes para que o incremento fosse mensurado.

$\mathrm{O}$ efeito das mantas geotêxteis sobre a sobrevivência e o incremento agiu de forma independente, pois as espécies com maiores percentuais de indivíduos sobreviventes não foram as mesmas espécies com maiores incrementos alométricos e vice-versa. Esse padrão foi similar ao verificado no grupo-controle do experimento.

$\mathrm{O}$ efeito das mantas geotêxteis para controle de Melinis minutiflora Beauv. sobre a sobrevivência e o incremento de mudas mostrou-se dependente da espécie arbórea utilizada.

\section{Agradecimentos}

Os autores agradecem ao Projeto Poranga o financiamento para implantação do experimento, à empresa Deflor Bioengenharia pela doação das mantas geotêxteis, à Coordenação de Aperfeiçoamento de Pessoal de Nível Superior (Capes), pela bolsa concedida, e ao Jardim Botânico de Brasília, pela hospedagem do experimento.

\section{Referências}

ANTEZANA, F. L. Crescimento inicial de 15 espécies do Bioma Cerrado sob diferentes condições de adubação e roçagem, em Planaltina - DF. 2008. 84 f. Dissertação (Mestrado em Ciências Florestais) - Universidade de Brasília, Brasília, 2008.

BARBARICK, K. A.; IPPOLITO, J. A. Nitrogen fertilizer equivalency of sewage sludge biosolids applied to dryland winter wheat. Journal of Environmental Quality, Madison, v. 28, n. 7, p. 1345-1351, 2000.

CORREAA, R. S. Recuperação de áreas degradadas pela mineração no Cerrado: manual para revegetação. 2. ed. Brasília: Universa, 2009. 174 p.

CORRÊA, R. S. et al. Eficiência agronômica de dois resíduos orgânicos na revegetação do horizonte C de um Latossolo Vermelho. Revista Ciência Agronômica, Fortaleza, v. 39, n. 4, p. 503-510, 2008.

CORRÊA, R. S. et al. Floristic wood composition of revegetated mining sites in the Brazilian Federal District. Bioscience Journal, Uberlândia, v. 31, n. 3, p. 908-922, 2015.

DISTRITO FEDERAL. Decreto no 17.277 de 11 de abril de 1996. Dá nova redação ao artigo 1ํㅜ , do Decreto n. ${ }^{-14.442}$ de 26 de novembro de 1992. Disponível em: <http://www.semarh.df.gov.br/ sites/300/379/00001402.pdf>. Acesso em 19 março 2011.

EMBRAPA. Centro Nacional de Pesquisa de Solos. Manual de métodos de análise de solo. 2. ed. Rio de Janeiro, 1997. 212p.

EMBRAPA. Centro Nacional de Pesquisa de Solos. Sistema brasileiro de classificação de solos. 4. ed. Rio de Janeiro, 2014. 376 p. 
FELFILI, J. M. et al. Desenvolvimento inicial de espécies de Mata de Galeria. In: RIBEIRO, J. F.; FONSECA, C. E. L.; SOUSA-SILVA, J. C. (Ed.). Cerrado: caracterização e recuperação de matas de galeria. Planaltina: EMBRAPA Cerrados, 2001. p. 779-811.

FONSECA, C. E. L. et al. Recuperação da vegetação de Matas de Galeria: estudos de caso no Distrito Federal e Entornos. In: RIBEIRO, J. F.; FONSECA, C. E. L; SOUSA-SILVA, J. C. (Ed.). Cerrado: caracterização e recuperação de matas de galeria. Planaltina: EMBRAPA Cerrados, 2001. p. 815-870.

GONÇALVES, J. L. M. et al. An evaluation of minimum and intensive soil preparation regarding fertility and tree nutrition. In: GONÇALVES, J. L. M.; BENEDETTI, V. (Org.). Forest nutrition and fertilization. Piracicaba: Instituto de Pesquisas Florestais e Estudos Florestais, 2004. p. 1364 .

HARIDASAN, M. Nutrição mineral de plantas nativas do Cerrado. Revista Brasileira de Fisiologia Vegetal, Campinas, v. 12, n. 1, p. 54-64, 2000.

HOLANDA, F. S. R.; ROCHA I. P.; OLIVEIRA, V. S. Estabilização de taludes marginais com técnicas de bioengenharia de solos no Baixo São Francisco. Revista Brasileira de Engenharia Agrícola e Ambiental, Campina Grande, v. 12, n. 6, p. 570-575, 2008.

INTERNATIONAL UNION FOR CONSERVATION OF NATURE. [Website]. [2010]. Disponível em: <http://www.iucn.org/about/work/programmes/pa/paproducts/wcpacategories>. Acesso em: 18 dez. 2010.

KLINK, C. A.; MACHADO, R. B. A conservação do cerrado brasileiro. Megadiversidade, Belo Horizonte, v. 1, n. 1, p. 147-155, 2005.

LORENZI, H. Árvores Brasileiras: manual de identificação e cultivo de plantas arbóreas nativas do Brasil. Nova Odessa: Plantarum, 2002a. v. 1. 384 p.

LORENZI, H. Árvores Brasileiras: manual de identificação e cultivo de plantas arbóreas nativas do Brasil. Nova Odessa: Plantarum, 2002b. v. 2. 384 p.

MACHADO, R. B. et al. Estimativas de perda daárea do Cerrado brasileiro. Brasília: Conservação Internacional, 2004. Relatório técnico não publicado. 26 p.

MARTINS, C. R. et al. Capim-gordura (Melinis minutiflora P. Beauv.), uma gramínea exótica que compromete a recuperação de áreas degradadas em unidades de conservação. Revista Árvore, Viçosa, MG, v. 28, n. 5, p. 739-747, 2004.

MARTINS, C. R. et al. Levantamento das gramíneas exóticas do Parque Nacional de Brasília, Distrito Federal. Natureza e Conservação, Curitiba, v. 5, n. 2, p. 23-30, 2007.

MENDONÇA, R. C. Flora vascular do bioma Cerrado: checklist com 12.356 espécies. In: SANO, S. M.; ALMEIDA, S. P.; RIBEIRO, J. F. (Ed.). Cerrado: ecologia e flora. Planaltina: EMBRAPA Cerrados, 2008. v. 2. p. 421-1279.

MOCHIUTTI, S. et al. Fitossociologia dos estratos arbóreo e de regeneração natural em um povoamento de acácia-negra (Acacia mearnsii Wild.) na região da Floresta Estacional Semidecidual do Rio Grande do Sul. Ciência Florestal, Santa Maria, v. 18, n. 2, p. 207-222, 2008.

MOURA, A. C. C. Recuperação de áreas degradadas no Ribeirão do Gama e o envolvimento da comunidade do núcleo hortícola de Vargem Bonita, DF. 2008. 111 f. Dissertação (Mestrado em Ciências Florestais) - Universidade de Brasília, Brasília, 2008.

PINTO, J. R. et al. Sobrevivência de espécies vegetais nativas do Cerrado, implantadas segundo o modelo MDR Cerrado para recuperação de áreas degradadas. In: CONGRESSO DE ECOLOGIA DO BRASIL, 8., 2007, Caxambu. Anais... [S.1.: s.n.], 2007.

POLSTER, D. F. Soil bioengineering techniques for riparian restoration. In: ANNUAL BRITISH 
COLUMBiA MINE SYMPOSIUM, 26., 2002, Dwason Creek. Proceedings... Dwason Ceek: [s. n.], 2002. p. 230-239.

REZENDE, A. V. et al. Comparação de modelos matemáticos para estimativa do volume, biomassa e estoque de carbono da vegetação lenhosa de um cerrado sensu stricto em Brasília, DF. Scientia Forestalis, Piracicaba, n. 71, p. 65-76, 2006.

RIBEIRO, J. F.; WALTER, B. M. T. Fitofisionomias do bioma Cerrado. In. SANO, S. M.; ALMEIDA, S. P. (Ed.). Cerrado: ambiente e flora. Planaltina: EMBRAPA; CPAC, 1998. p. 89-166.

ROCHA, I. P. Controle da erosão marginal no baixo São Francisco: uso da bioengenharia de solos associada à recuperação da vegetação ciliar. 2006. 60 f. Monografia (Graduação) Universidade Federal de Sergipe, Sergipe, 2006.

SILVA JÚNIOR, M. C. et al. Análise florística de matas de galeria no Distrito Federal. In: RIBEIRO, J. F. Cerrado - Matas de Galeria. Planaltina: EMBRAPA; CPAC, 1998. p. 52-84.

SILVA JÚNIOR, M. C. et al. Análise da flora arbórea de Matas de Galeria no Distrito Federal: 21 levantamentos. In: RIBEIRO, J. F.; FONSECA, C. E. L.; SOUSA-SILVA, J. C. Cerrado: caracterização e recuperação de Matas de Galeria. Planaltina: EMBRAPA Cerrados, 2001. p. 142191.

SILVA JÚNIOR, M. C.; PEREIRA, B. A. S. +100 árvores do cerrado - Matas de Galeria: guia de campo. Brasília: Ed. Rede de Sementes do Cerrado, 2009. 288 p.

SILVA, R. P. Alometria, estoque e dinâmica da biomassa de florestas primárias e secundárias da região de Manaus (AM). 2007. 152 f. Tese (Doutorado em Ciências de Florestas Tropicais) Universidade Federal do Amazonas, Manaus, 2007.

SNEDECOR, G. W.; COCHRAN, W. G. Statistical methods. 8. ed. Ames: Iowa State University Press, 1989. 503 p.

SOUZA, C. C. Estabelecimento e crescimento inicial de espécies florestais e plantios de recuperação de matas de galeria do Distrito Federal. 2002. 91 f. Dissertação (Mestrado em Ciências Florestais) - Universidade de Brasília, Brasília, 2002.

VAZ, L. M. S.; GONÇALVES, J. L. M. Uso de biossólidos em povoamento de eucalipto: Efeito em atributos químicos do solo, no crescimento e na absorção de nutrientes. Revista Brasileira de Ciência do Solo, Viçosa, MG, v. 26, n. 3, p. 747-758, 2002. 